\title{
Transforming the image of a rural space into a photorealistic virtual reality and opening to a sustainable development
}

\author{
Mihai Simon $^{1}$ (i) , Loredana Copăcean ${ }^{1 *}$ (i) , Cosmin Popescu ${ }^{1}$ (i) and Luminiţa \\ Cojocariu ${ }^{1,2 *}$
}

${ }^{1}$ Banat's University of Agricultural Sciences and Veterinary Medicine"King Mihai I of Romania" from Timisoara, 300645, 119, Calea Aradului, Timisoara, Romania;

2 Agricultural Research and Development Station Lovrin, 307250, 200, Principala, Lovrin, Romania;

*Correspondence: Iorecopacean@yahoo.com; Tel. 0729591651 (L.C.); luminitacojocariu@yahoo.com; Tel. 0741102902 (L.C.)

Keywords: LiDAR; rural development; spheric images; TruView; JetStream.

\begin{abstract}
The aim of the research was to create an "improved" virtual tour, which would allow the transformation of the image of a rural space into photorealistic virtual reality, through mobile scanning equipment and geomatic technique, to meet practical requirements: evaluation of the agricultural potential of the area, evaluation of the tourist potential, reconstruction of the urban space, territorial planning, etc, but also with theoretical implications in the scientific research in the field. The area of interest was scanned with the Leica Pegasus Backpack, a platform for capturing reality. With the help of the acquired data, a virtual tour of this village was made similar to Google Street View, but more complex due to the fact that LiDAR data were also purchased in addition to images during the scan, thus having the possibility to perform various measurements within virtual tour, made with Leica TruView and JetStream software. The inclusion of data in the virtual tour offers, in addition to measurable elements and the possibility of summative analysis of all components of physical space, from "strengths" to "opportunities" and "risks", data that are needed in the process of planning and sustainable development of space.
\end{abstract}

\section{Introduction}

The first historical mentions about Labasowcz (Labaşint at present), outline the image of a community, 450 years ago, "numerous and rich" from the Şoimoş Fortress (Munteanu, 2007; Rusu, 2007). In 1924, the SOCEC Yearbook, published in Bucharest, mentions Labaşint as a prosperous community, with over 500 inhabitants. With the industrialization and development of the surrounding cities, the population has decreased significantly (Bocu, 2005), these cities being "poles of attraction", especially for socio-economic reasons.

Gradually, the locality became massively depopulated, and currently, in Labaşint, less than ten inhabitants live (Labaşint City Hall). The old houses were demolished and only in a few places there are a few more houses rebuilt and the village church, which remained a witness to the passage of time.

In the context of sustainable development, the study area has several dominant features: the absence of the human component and the diversity of natural environment resources, specific to disadvantaged areas of Banat (Căluşeru et al., 2015), especially areas of grasslands, forests or geological resources (Copacean et al., 2019). From this 
balance, it appears the under-exploitation of these resources but also the "invitation" to exploit this space, for the decision-makers at regional level.

In this context, one of the ways to investigate, evaluate and present the natural potential of the area of interest is to introduce geomatic technology, either by aerial scanning - UAV (Enea et al., 2018; Simon et al., 2020), or by terrestrial scanning - mobile scanner (Oludare et al., 2016; Mita et al., 2020).

The resulting point clouds, but also the photos can be used to create virtual tours (VT) that present the reality in detail, with all its associated effects (González-Delgado et al., 2015; Spielmann, Mantonakis, 2018; Manish et al., 2021) and which can be transmitted online, with the intention of authentically recreating the real experience of the site (Aguilera et al., 2014).

Fineschi et al. (2015) define the virtual tour (VT) as consisting of a series of merged images that we can visit the location in front of the computer. A virtual tour uses panoramic images (Wessels, 2014) that allow visitors to see the village as if in the middle of the streets, including the possibility to return to $360^{\circ}$.

Unlike Google Street View, in the application made in this study, LiDAR data were also included, thus obtaining images during the scan, which offers the possibility to perform various measurements, in town, but also in agricultural space.

The aim of the research was to create an "improved" virtual tour, which would allow the transformation of the image of a rural area into photorealistic virtual reality, through mobile scanning equipment and geomatic technique, to meet practical requirements: assessing the agricultural potential of area, evaluation of the tourist potential, reconstruction of the urban space, planning, etc. but also with theoretical implications in the scientific research in the field.

\section{Materials and Methods}

\subsection{Study area}

The research presented in this paper was carried out in Labaşint village, Şiştarovăt commune from Arad county (Figure 1), a village that is in the category of abandoned localities where less than ten inhabitants live. The village is located in the Hills of Lipova, a hilly area, fragmented by numerous surface courses (Boia, 2015).

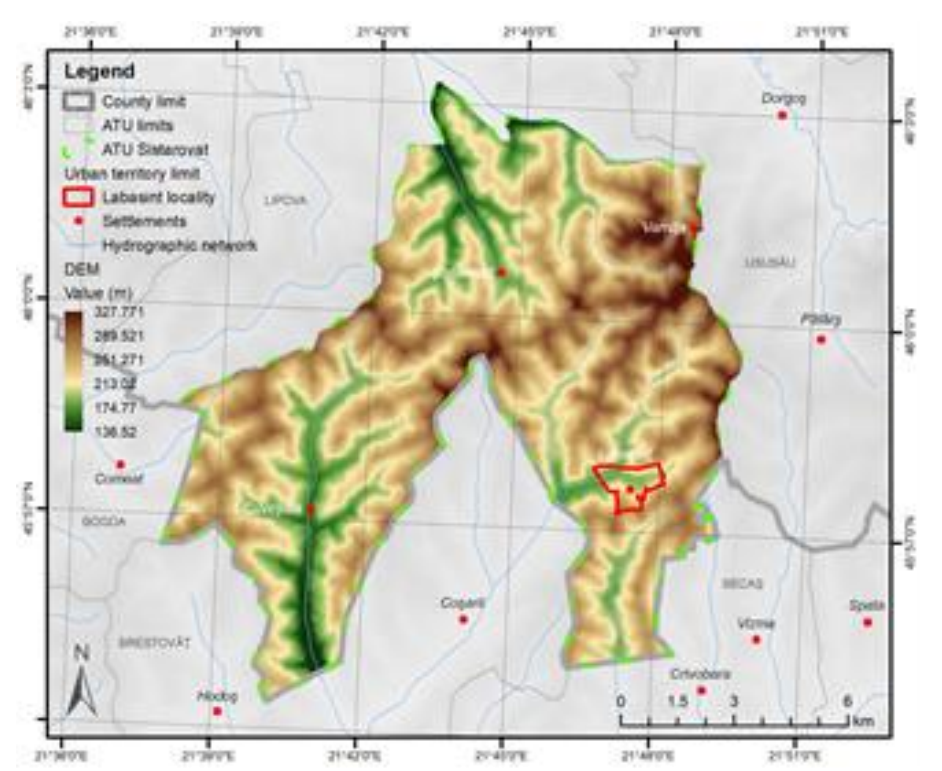

Figure 1. Location of the study area (Processing after EEA-DEM, 2017; , Romania: general vector data sets, 2021; ABA Banat, 2020) 


\subsection{Applied methodology}

The working methodology that was the basis of this study was divided into several stages presented in Figure 2.

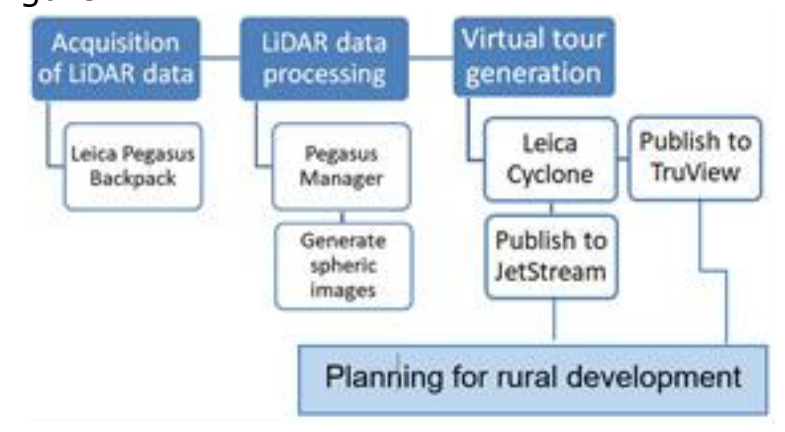

Figure 2. Research methodology

The working methodology was divided into three stages: LiDAR data acquisition, data processing and based on them, virtual tour generation. LiDAR data was exported for use on two platforms, TruView and JetStream. The quantitative and qualitative interpretation of the data resulting from the virtual tour, offers support in the process of territorial planning towards the development of the analyzed area.

\subsection{Equipment used for data collection}

The equipment used, LiDAR Backpack terrestrial scanner (Figure 3), includes:

- GNSS receiver that includes 3 L-Band, SBAS and QZSS bands for the GPS-NAVSTAR, GLONASS, Galileo and BeiDou constellations;

- two Velodyne VLP-16 LiDAR scanning systems with a horizontal field of view of $270^{\circ}$ and a vertical field of view of $30^{\circ}$, which allow the capture of 600.000 points per second at a usable distance of 60 meters;

- five 4MP cameras each offering $360 \times 200$ panoramic images, with a pixel size of $5.5 \times$ 5.5 microns;

- an Inertial Measurements Units (IMU) consisting of three axes with a gyroscope and accelerometer;

- a light sensor, a 1TB SSD Multicore industrial computer inside the backpack with Windows operating system;

- a Panasonic tablet for mission control;

- additional ports for attaching another LiDAR system, a camera with multispectral sensors or a georadar (Leica Pegasus:Backpack, 2021).

The combination of INS systems with GNSS technologies has led to the creation of a control and positioning system that can be used in precision navigation. Capturing $360^{\circ}$ images eliminates the risk of repeating or overlapping images of objects (Castagnetti, 2017).

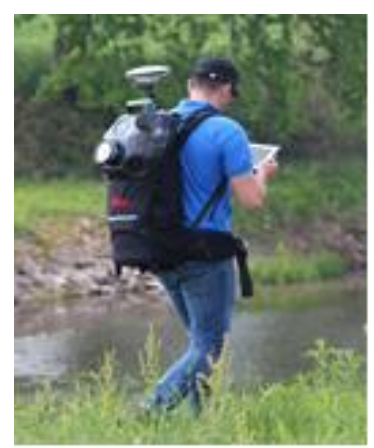

Figure 3. Leica Pegasus Backpack equipment 


\subsection{Software components used}

The following software was used for preprocessing, processing and representation of geospatial data:

- Pegasus Manager (Leica Pegasus Manager, 2021) for processing data purchased with Leica Backpack equipment and for generating spherical images;

- Leica Cyclone (Leica Cyclone, 2021) for export to TruView and JetStream;

- TruView (Leica TruView, 2021) and JetStream (Jetstream User Guide, 2021) for viewing the virtual tour.

\subsection{Data acquisition}

The area of interest in this study was scanned with the Leica Pegasus: Backpack equipment, this being a platform of reality capture sensors that collects data indoors, outdoors but also underground (Mita et al., 2020; Șmuleac, et al., 2020).

Within this study, two scans were performed (walk_A and walk_B), which represent the roads in the built-up area of Labaşint locality, represented in Figure 4 by the colors blue and red. The first road, walk_A, has a length of $1.9 \mathrm{~km}$, and the second road, walk_B, has a length of $1.2 \mathrm{~km}$. Thanks to the Mobile Mapping System technology, the data acquisition was done in approx. 30 minutes.

\subsection{Data processing}

The processing of the obtained data was performed in Pegasus Manager (Figure 4), where there is the possibility to generate spherical images for creating virtual tours.

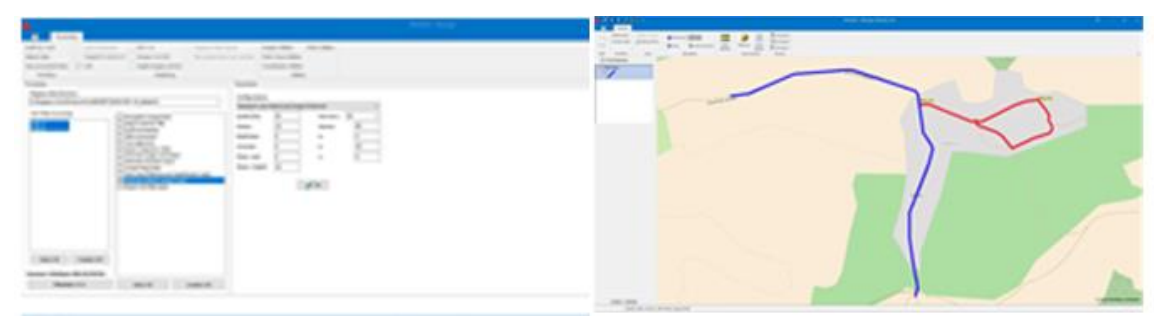

Figure 4. View the route in Pegasus Manager

By applying the procedures described above, point clouds result, which can be viewed orthographically or three-dimensionally (Julin et al., 2020; Pfeifer et al., 2021). There is also the possibility of visualizing spherical images (Fig. 5), which offers the possibility of detailed spatial analysis.

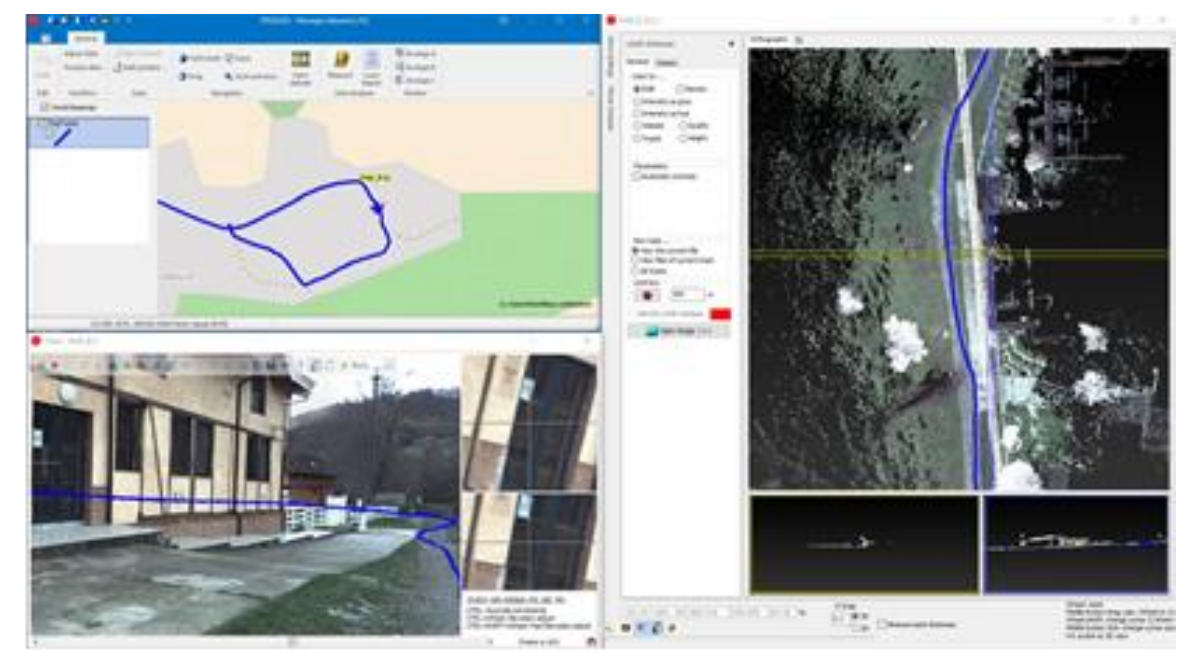

Figure 5. Identify the details on the spherical images 
Applicable to any space, interior or exterior, the way of presentation through spherical images, positions us inside a "virtual globe" that allows us to fully and integratedly explore space. These images were obtained by combining the images from the 5 cameras of the Pegasus Backpack equipment (Figure 6).

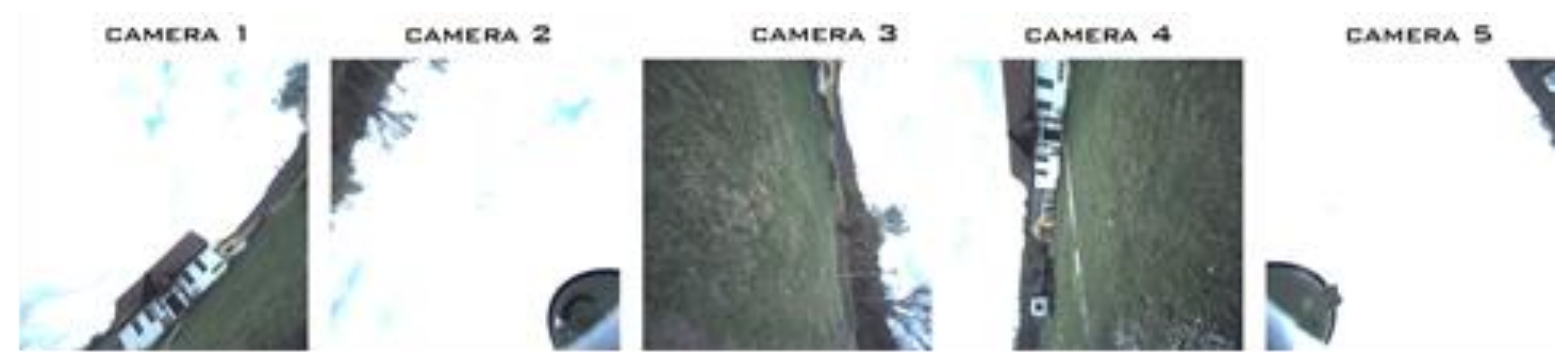

Figure 6. Images captured with Pegasus Backpack equipment

The five cameras were set to capture images at a distance of 2 meters. Thus, during the first road (walk_A), at a distance of $1.9 \mathrm{~km}, 9.135$ images were purchased. From the second scan (walk_B), 5.770 images were obtained over a length of $1.2 \mathrm{~km}$. All these 14.905 images were used to generate the spherical images, shown in Figure 7 , resulting in 1.827 spherical images for walk_A and 1.154, for walk_B.

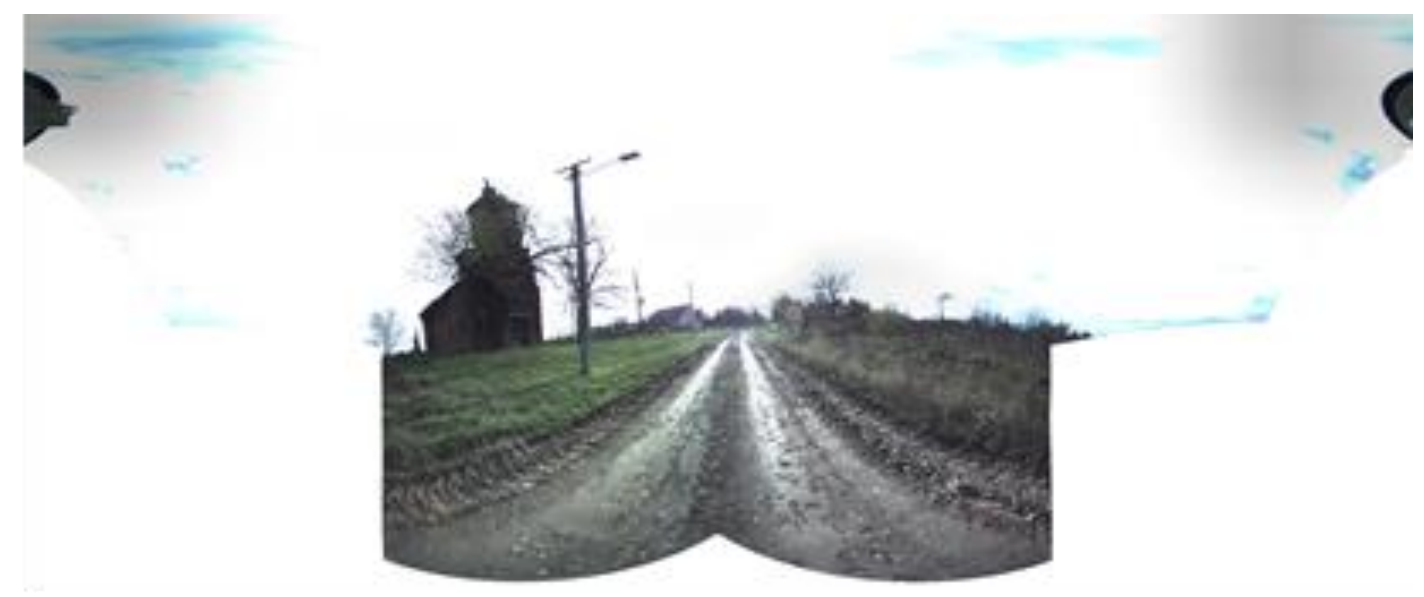

Figure 7. Spherical image of the area of interest

Figure 8 shows the point cloud of LiDAR, colored according to the two paths (walks), height or RGB (composite image in natural colors) where each LiDAR point is associated by the color of the corresponding pixel in the images taken during the scan.

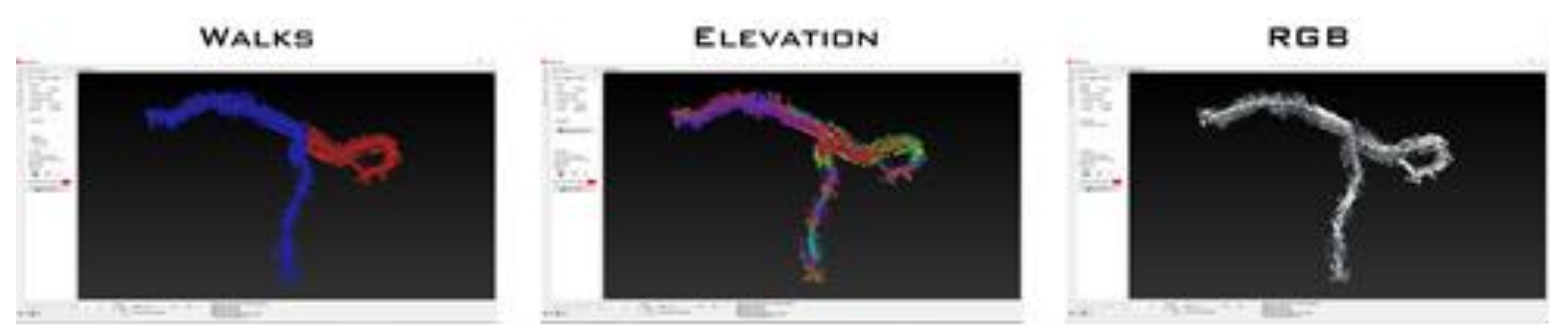

Figure 8. Symbolization of point clouds

The point cloud obtained in the previous stage was imported into Leica Cyclone where we have the possibility to export for TruView or JetStream using the Publish to TruView and Publish to JetStream functions (Fig. 9). 

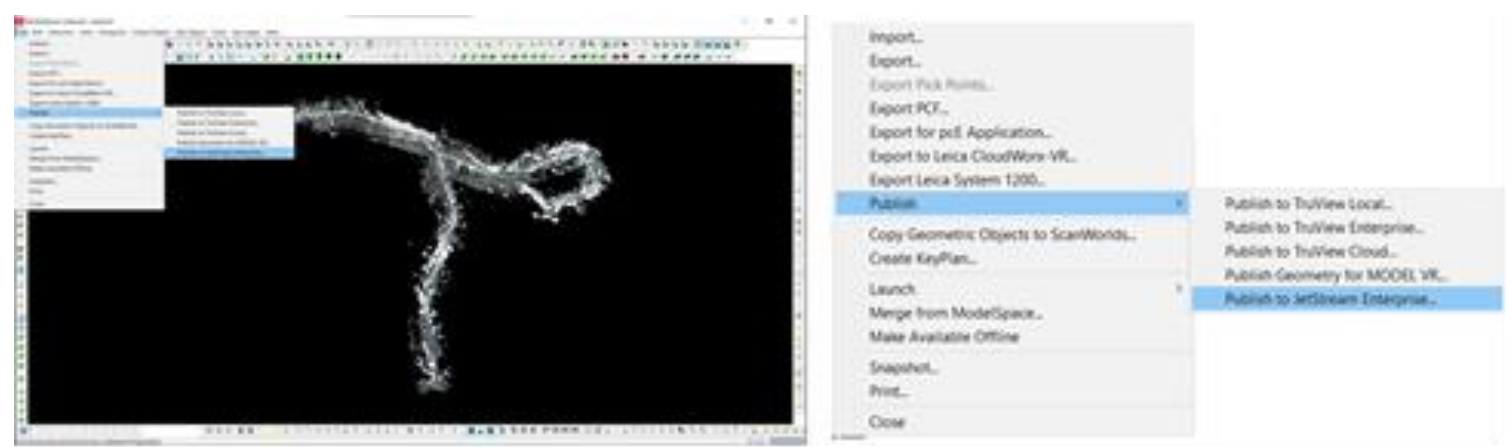

Figure 9. Export to TruView or JetStream

\section{Results}

3.1. Designing an "improved" virtual tour by transforming the image into a photorealistic virtual reality

This section presents, from a distance, a "virtual tour" of Labaşint, a program developed as a necessity nowadays when more and more people stay at home and surf online as a result of the crisis caused by COVID-19.

Through the Leica TruView and JetStream software, an interactive model (virtual tour) can be created that allows navigation within the scan, where it is possible to move between different areas (Oludare et al., 2016) and perform operations, including distance measurements, text insertion, instant printing, coordinate insertion directly from photos and measured points (Suding, 2019).

For the presentation and visualization of the streets in the built-up area of Labaşint village, a virtual tour of the objective was created, which can be accessed directly in Internet Explorer. To view this data we need the TruView Pack \& Go and/or JetStream software which can be downloaded for free from the official Leica Geosystems website (Figure 10).

The TruView site map is a panoramic image of the data, the viewpoint being located in the same location as our scanner that captured the point clouds. In our case, we decided that the locations should be located every 10 meters in the middle of the streets.
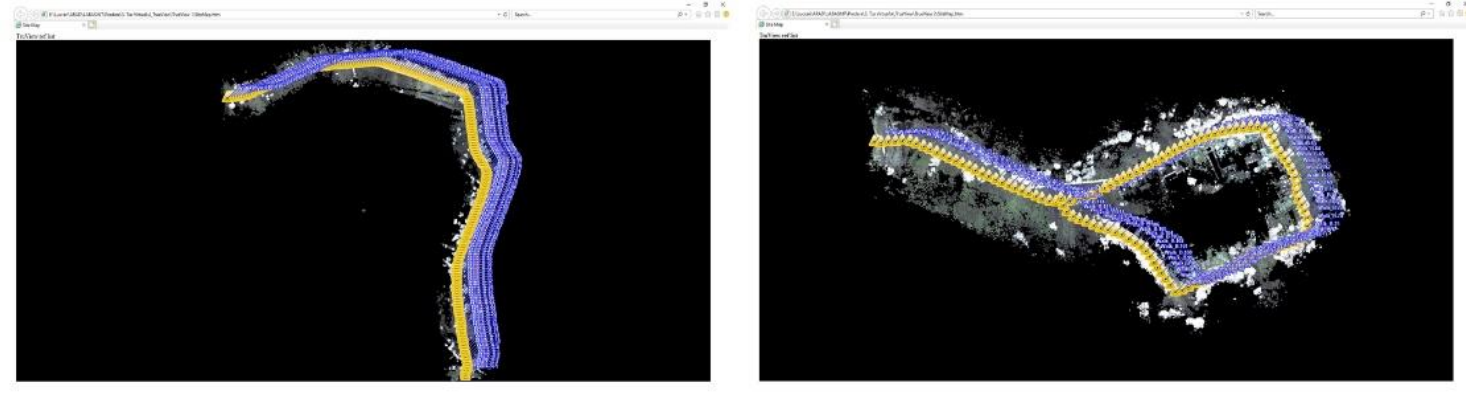

Figure 10. Location of TruView sites

With the help of the TruView application it is possible to make, around the scene, magnifications and reductions, the extraction of the dimensions from one point to another, the extraction of coordinates but it will not be possible to "fly" around the scene as in some 3D systems.

With Leica TruView software we can access any kind of data remotely, from any device (laptop, tablet or phone) through the Internet Explorer browser. This flexibility allows us to view projects or perform simple data queries (Figure 11). 

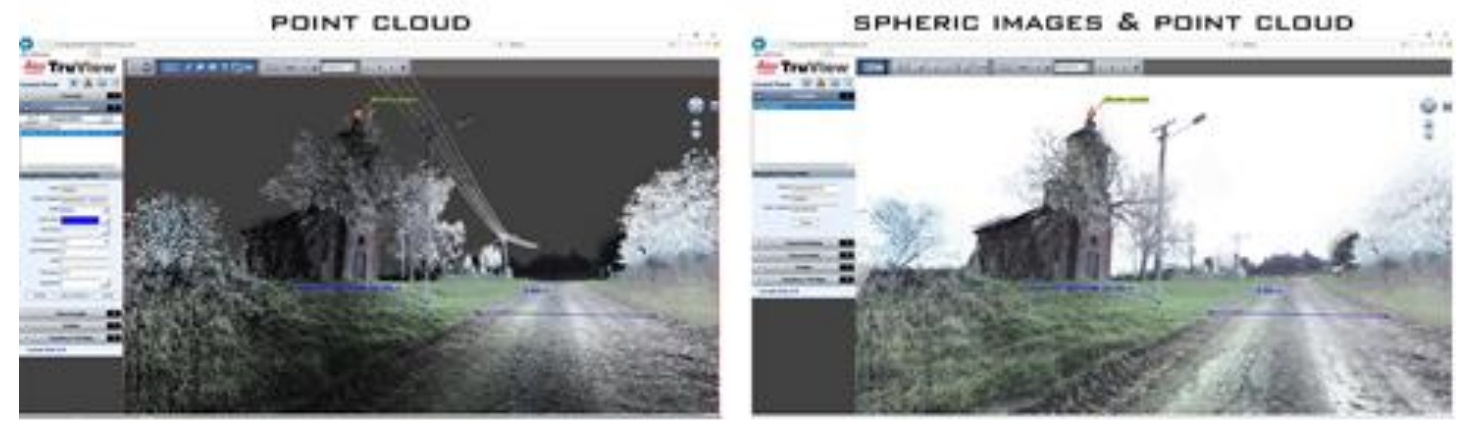

Figure 11. View the virtual tour and take measurements in TruView

Another similar but much newer and more complex program in which virtual tours can be viewed is JetStream. It is quite similar to TruView, only it cannot be accessed through Internt Explorer, but the image quality is much better.

As we can see in Figure 12, the location sites is similar to that in TruView, the locations being the same at distances of 10 meters. To open one of the locations select the corresponding section and the software will open the panoramic image from that location.
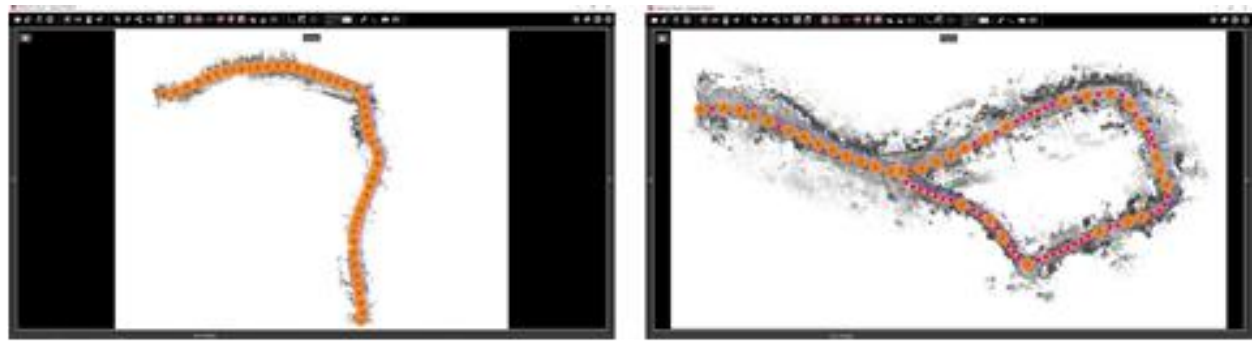

Figure 12. Location of JetStream sites

Unlike TruView, in JetStrem we have 3 possibilities for data visualization: image visualization, point cloud visualization or overlapping of the two data types (Figure 13). To navigate forward or backward, select the corresponding icon, depending on the direction you want to follow. Navigating in JestStream is very easy, similar to Google Street View. If we choose to view the images superimposed over the point clouds, there is the possibility of performing different measurements.

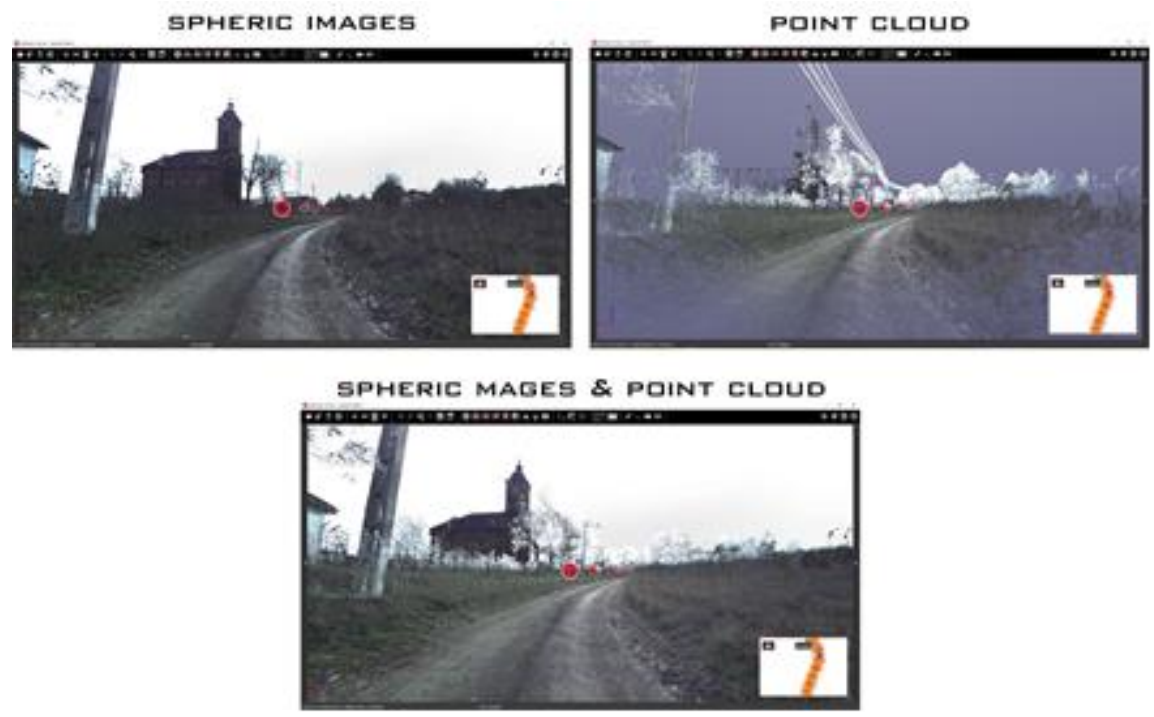

Figure 13. View the virtual tour in JetStream 
In the JetStream software we have the possibility to explore Labaşint village from one end to the other, being similar to Google Street View. Presentation videos, coordinate extraction or distance measurements can be made (Figure 14). In addition to the virtual tour function, JetStream is one of the many powerful tools in the Leica suite for working with laser scanning. It is also important that large data sets can be made, faster and easier to manage, in the analysis of the space under study.

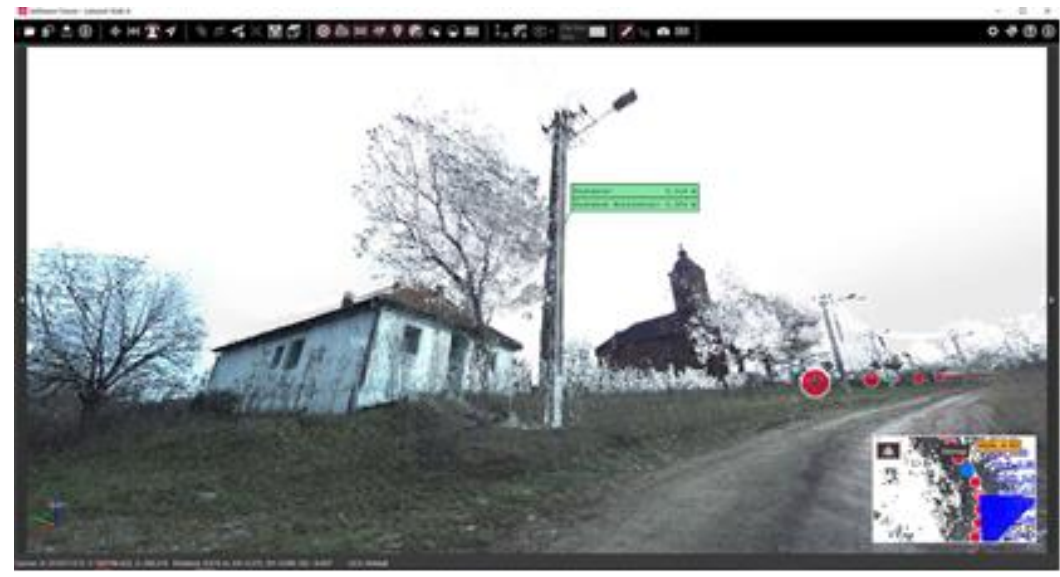

Figure 14. Example of measurements in JetStream

JetStream has proven to be a very suitable and flexible software for creating a VT, which involves a theoretical but also a practical component; requires small investment and provides visitors with a range of tools (informative data) that facilitate learning (Osman, Aziz, 2021) and ensure the future of interactivity.

\section{Discussion}

\subsection{Assessing the potential of the area and opening up to sustainable rural development}

The virtual tour of Labaşint provides data, less accessible given the isolation and even abandonment of the village, about the agricultural space: pastures, forests and little arable land (Fig. 15) and about raising animals in traditional systems (Fig. 16), this being the main production activity in the locality.
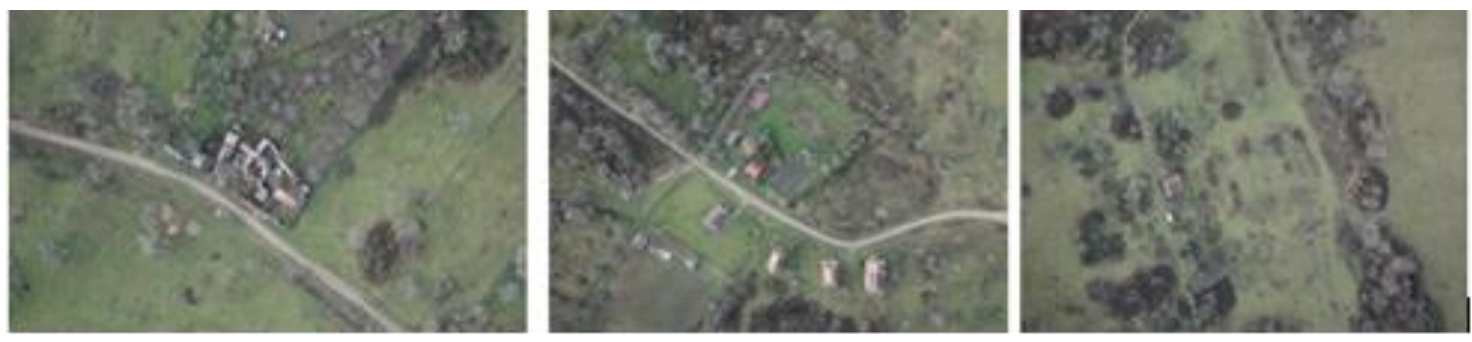

Figure 15. The configuration of the agricultural space in Labaşint locality
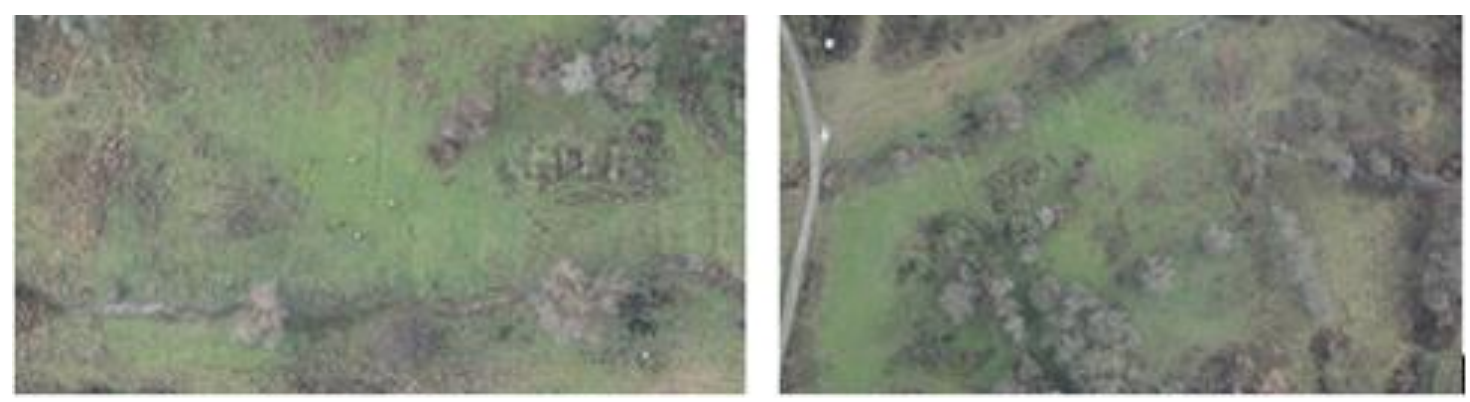

Figure 16. Traditional agricultural practices 
Data on the distribution of grasslands, the main economic resource in Labaşint locality, are important for: monitoring these habitats and analyzing the nature of phenomena such as climate change; it provides a means of assessing carbon stocks and last but not least defending biodiversity. The grasslands were identified on approx. $80 \%$ of the scanned area, in an advanced state of degradation, included in agro - forestry pastoral systems.

Globally, agro-forestry-pastoral systems promote sustainable agriculture (Copăcean et al., 2020) ensure increased land efficiency, environmental protection and biodiversity conservation (Cojocariu et al., 2019).

Corresponding to the physical-geographical factors, the vegetation of the grasslands is varied and rich in species characteristic of the continental flora. It is dominated by plants from the grass family, some good fodder such as Dactylis glomerata, Festuca pratensis, the highest proportion being Lolium perenne (Mâşu et al., 2018) and a series of valuable perennial legumes. Due to the under-exploitation of the grasslands and the lack of care works, Carduus nutans also appears, isolated or in clusters (Cojocariu et al., 2017), as well as trees and shrubs.

Starting with 2008, farmers in Labaşint locality are rewarded, through subsidies Agri-environment and climate measure (Ministry of Agriculture and Rural Development, 2019) for maintaining High Natural Value (HNV) grasslands if their management practices encourage spontaneous flora and fauna wild (Căluşeru et al., 2013).

Agrotourism, in Labaşint locality, would represent a future challenge and at the same time, the way to support sustainable development (Adamov et al., 2020). The virtual tour shows the "realistic" image of the area and can be accessed online by all stakeholders (individuals, travel agencies, developers, etc.). It can also be used in promotional materials or in development strategies to argue the tourist values of the area.

\section{Conclusions}

Documentation and presentation of the virtual space became possible and popular with the introduction of new technologies, equipment and software.

With the outbreak of Covid-19, on days when people are isolated, the solution of the virtual tour is perfect to view locations without leaving the house.

The virtual tour of Labaşint locality is a safe alternative to real site visits and is the most modern and efficient method of promoting the countryside.

By scanning with LiDAR equipment can be extracted both topo-cadastral information and physical-geographical data particularly useful in assessing the natural potential of the area. Indirectly, by interpreting the images, some socio-economic aspects can be deduced to outline the anthropic framework.

The inclusion of data in the virtual tour offers, in addition to the measurable elements, the possibility of summative analysis of all components of physical space from "strengths" to "opportunities" and "risks". Such information is necessary for managers of tourist and cultural sites, because it becomes more important than ever to interact with potential online visitors.

In other words, the images "talk" about an area where sustainable agriculture can be practiced through the use of traditional practices of using grasslands and animal husbandry. The use of subsidies for grasslands with High Natural Value (HNV) can contribute to the conservation and conservation of flora and fauna characteristic of grasslands habitats and implicitly to the economic development of Labaşint locality,

\section{References}


1. Adamov, T.; Ciolac, R.; Iancu, T.; Brad, I.; Peț, E.; Popescu, G.; Șmuleac, L. (2020), Sustainability of Agritourism Activity. Initiatives and Challenges in Romanian Mountain Rural Regions. Sustainability; 12(6): 2020, pp. 2502. https://doi.org/10.3390/su12062502

2. Aguilera, J.; Alonso, F.; Gomez, J. (2014), Generating Three-Dimensional Virtual Tours from Two-Dimensional Images. United States Patent No. US 8,705,892 B2, https://patents.google.com/patent/US8705892B2/en

3. Arhiva Administraţiei Bazinale de Apă Banat

4. Bocu, S. (2005), Drumuri și răscruci. Memorii (ediție îngrijită de Cornel Ungureanu și Viorel Marineasa), Ed. Marineasa, Timișoara

5. Boia, S.I. (2015), Șiștarovăț. Monografie, Vasile Goldiș University Press, Arad

6. Castagnetti, C.; Mancini, F.; Rivola, R.; Rossi, P.; Oppici, S.; Albano, V.; Formentini, M. (2017), Potenzialità dei nuovi sistemi indossabili per la scansione 3D - Una sperimentazione del Pegasus Backpack di Leica Geosystems presso il Palazzo Ducale di Modena. Archeomatica, 7(4)

7. Căluşeru, A.L.; Cojocariu, L.; Horablaga, M.N.; Bordean, D.M.; Horablaga, A.; Cojocariu, A.; Borozan, A.B.; Iancu, T. (2013), Romanian National Strategy for the conservation of biodiversity 2013-2020-integration of european environmental policies, SGEM Conference Proceedings, pp: 723-728, DOI: https://doi.org/10.5593/SGEM2013/BE5.V2/S23.013

8. Căluşeru, L.A.; Cojocariu, L.; Borlea, F.; Bordean, D.M.; Horablaga, A. (2015), Rural development of mountain areas in Romania, challenges and targets for the year 2020, SGEM 2015 Conference Proceedings, Book5 Vol. 2, pp. 791-798 pp, DOI: https://doi.org/10.5593/SGEM2015/B52/S23.10

9. Cojocariu, L.; Bordean, D.M.; Breica Borozan, A.; Nita, S.; Horablaga, A. (2017), Carduus nutans $L$ and the effect on the heavy metals and microenvironment biota, REV. CHIM, V. 68, No 7, pp. 1524 - 1527, DOI: https://doi.org/10.37358/RC.17.7.5708

10. Cojocariu, L.; Copăcean, L.; Popescu, C. (2019), Conservation of grassland habitats biodiversity in the context of sustainable development of mountain area of Romania, Applied Ecology and Environmental Research, vol. 17(4): pp. 8877-8894, DOI: https://dx.doi.org/10.15666/aeer/1704_88778894

11. Copacean, L.; Zisu, I.; Mazare, V.; Cojocariu, L. (2019), Analysis of Land Use Changes and their influence on Soil Features. Case Study: Secaș Village, Timiș County (Romania), Present Environment and Sustainable Development, PESD, vol. 13, no.2, pp. $157-166$

12. Copăcean, L.; Cojocariu, L.; Simon, M.; Zisu, I.; Popescu, C. (2020), Geomatic techniques applied for remote determination of the hay quantity in agro-silvo-pastoral systems, Present Environment and Sustainable Development, PESD, vol. 14, no. 2, pp. 89-101

13. Enea, A.; Iosub, M.; Stoleriu, C.; Ursu, A.; Romanescu, G. (2018). The drone - a methodological tool, for generating base layers in GIS. International Scientific Conference Geobalcanica, pp. 513-520. DOI: https://doi.org/10.18509/GBP.2018.56.

14. European Environment Agency (EEA) (2017): Digital Elevation Model (DEM), Produced using Copernicus data and information funded by the EU, https://www.eea.europa.eu/data-and-maps/data/copernicus-land-monitoring-service-eu-d em

15. Fineschi, A.; Pozzebon, A. (2015), A 3D virtual tour of the Santa Maria della Scala Museum Complex in Siena, Italy, based on the use of Oculus Rift HMD, International Conference on 3D Imaging (IC3D), Liege, Belgium, pp. 1-5

16. González-Delgado, J.A.; Martínez-Graña, A.M.; Civis, J. et al. (2015), Virtual 3D tour of the Neogene palaeontological heritage of Huelva (Guadalquivir Basin, Spain). Environ Earth Sci 73, pp. $4609-4618$

17. Julin, A.; Kurkela, M.; Rantanen, T.; Virtanen, J.-P.; Maksimainen, M.; Kukko, A.; Kaartinen, H.; Vaaja, M.T.; Hyyppä, J.; Hyyppä, H. (2020), Evaluating the Quality of TLS Point Cloud Colorization. Remote Sens., 12, 2748. https://doi.org/10.3390/rs12172748

18. Jetstream User Guide: https://portal.xsede.org/jetstream

19. Labaşint City Hall, judeţul Arad, https://www.primariasistarovat.ro/

20. LeicaPegasus:Manager:https://leica-geosystems.com/products/mobile-sensor-platforms/sof tware/leica-pegasus-manager 
21. Leica TruView Digital Reality Viewer: https://leica-geosystems.com/products/laser-scanners/software/leica-truview

22. Leica Cyclone 3D Point Cloud Processing Software: https://leica-geosystems.com/products/laser-scanners/software/leica-cyclone

23. Leica Pegasus:Backpack Wearable Mobile Mapping Solution: https://leica-geosystems.com/products/mobile-sensor-platforms/capture-platforms/leica-p egasus-backpack

24. Manish, R.; Lin, Y-C.; Ravi, R.; Hasheminasab, S.M.; Zhou, T.; Habib, A. (2021), Development of a Miniaturized Mobile Mapping System for In-Row, Under-Canopy Phenotyping. Remote Sensing; 13(2):276. https://doi.org/10.3390/rs13020276

25. Mâşu, S.; Cojocariu, L.; Grecu, E.; Morariu, F.; Bordean, D.M.; Horablaga, M.; Nita, L.; Nita, S. (2018), Lolium perenne - a phytoremediation option in case of total petroleum hydrocarbons polluted soils, REV. CHIM (Bucharest), V. 69, No 5, pp.1110 - 1114, DOI: https://doi.org/10.37358/RC.18.5.6270

26. Ministry of Agriculture and Rural Development, 2019, National Rural Development Program (PNDR 2014 - 2020), online:

http://www.madr.ro/docs/dezvoltare-rurala/2019/PNDR-2014-2020-versiunea-IX-aprobat a-23-ianuarie-2019.pdf

27. Mita, R.; Simon, M.; Copacean, L.; Smuleac, A.; Herbei, M.V.; Popescu, G. (2020), Using Geographical Information Systems in order to achieve the urban cadastre in the Subcetate neighborhood of Arad with the help of modern technologies, Research Journal of Agricultural Science, Vol. 52, Nr. 4, 2020, pp. 93 - 103

28. Munteanu, I. (2007), Banatul istoric. vol 2. Ocupaţii. Economia, Editura Excelsior Art, Timişoara, ISBN 978-973-592-191-0.

29. Oludare, M.; Pradhan, I.; Pradhan, P. (2016), A decade of modern cave surveying with terrestrial laser scanning: A review of sensors, method and application development. International Journal of Speleology, 45: pp. 71-88

30. Osman, S.; Aziz, H. (2021), Virtual Tours a Means to an End: An Analysis of Virtual Tours' Role in Tourism Recovery Post COVID-19, Journal of Travel Research 00(0), pp.1-21, DOI: https://doi.org/10.1177/0047287521997567

31. Pfeifer, N.; Falkner, J.; Bayr, A.; Eysn, L.; Ressl, C. (2021), Test Charts for Evaluating Imaging and Point Cloud Quality of Mobile Mapping Systems for Urban Street Space Acquisition, Remote Sensing 13, no. 2: 237. https://doi.org/10.3390/rs13020237

32. Romania: general vector data sets, - geospatial databases http://www.geo-spatial.org/download/romania-seturi-vectoriale

33. Rusu, R. (2007), Organizarea spaţiului geografic în Banat, Ed. Mirton, Timişoara

34. Simon, M.; Popescu, C.A.; Copăcean, L.; Cojocariu, L. (2020), Complex model based on UAV technology for investigating pastoral space. Present Environment and Sustainable Development. 14, pp. 139-150. DOI: https://doi.org/10.15551/pesd2020142011

35. Spielmann, N.; Mantonakis, A. (2018), In Virtuo: How User-Driven Interactivity in Virtual Tours Leads to Attitude Change. Journal of Business Research 88: pp. 255-64

36. Suding, A. (2019), Aktuelle Messtechnik zur Bestandsaufnahme von Kranbahnen. Stahlbau, 88: pp. 66-73

37. Șmuleac, A.; Șmuleac, L.; Man, T.E.; Popescu, C.A.; Imbrea, F.; Radulov, I.; Adamov, T.; Pașcalău, R. (2020), Use of Modern Technologies for the Conservation of Historical Heritage in Water Management. Water. 2020; 12(10):2895

38. Wessels, S.; Ruther, H.; Bhurtha, R.; Schroeder, R. (2014), Design and creation of a 3D virtual tour of the world heritage site of Petra, Jordan 